\title{
Maxillary sinus fungus ball as a cause for facial pain: Analysis of three cases
}

\author{
Yüz ağrısına neden olan maksiller sinüs fungus topu: Üç olgunun analizi
}

\section{Ceyhun AKSAKAL}

\begin{abstract}
Summary
The development of a sinus fungus ball (FB) is a form of non-invasive fungal sinusitis that generally affects immunocompetent individuals. In this report, 3 cases of maxillary sinus FB are described, including 1 bilateral maxillary sinus case. The fungal debris was cleared using endoscopic sinus surgery in each case. No recurrence was observed in follow-up at the $6^{\text {th }}, 7^{\text {th }}$, or $26^{\text {th }}$ month. The headache and facial pain symptoms of the patients improved. Efficient cleansing of the maxillary sinus, particularly the anterior wall, improves the recurrence ratio.
\end{abstract}

Keywords: Facial pain; fungus; maxillary.

\section{Özet}

Fungus Ball (FB) genellikle immüncompetent kişileri etkileyen non-invaziv bir fungal sinüzit şeklidir. Sıklıkla maksiller sinüsleri etkiler. Biz bu vaka sunumunda bir tanesi bilateral maksiller sinüsü tutan 3 hastadaki maksiller sinüs FB unu değerlendirdik. Bu vakaların tümünde fungal debris Endoskopik Sinüs Cerrahisi (ESC) ile temizlenmiştir. Vakaların ayrı ayrı 6, 7 ve 26. ayındaki takiplerinde rekürrens izlenmedi. Hastaların özelikle yüz ağrısı ve baş ağrısı semptomları tamamen gerilemiştir. Maksiller sinüsün özellikle anterior duvarının iyi bir şekilde temizlenmesi rekürrens oranlarını azaltacaktır.

Anahtar sözcükler: Yüz ağrısı; mantar; maksiller.

\section{Introduction}

Fungal Rhinosinusitis is categorized as invasive form and non-invasive form. Invasive form is generally seen at immunocompromised patients while noninvasive form is often seen at immunocompetent patients and fungus balls are also presented at this group. ${ }^{[1]}$ Infectious agent in fungus balls (FB) is usually Aspergillus spp. ${ }^{[2]}$

Despite being in the natural flora of nasal cavity and paranasal sinuses, saprophytes can cause sinonasal diseases in certain conditions. It is asserted that the anaerobic medium which is generated by hypoxia and hypoventilation depended low $\mathrm{pH}$ have a role in fungal ball pathogenesis. ${ }^{[3]} \mathrm{FB}$ mostly seen in maxillary sinus, and then sphenoid sinus, ethmoid sinus and frontal sinus respectively. ${ }^{[4]}$

$\mathrm{FB}$ is normally asymptomatic at the early stages of the disease. However, it causes various symptoms at the later stages. Nasal congestion, bloody or purulence postnasal drip, face pain and headache are some of those symptoms. ${ }^{[2,4]}$

In this case series, three patients underwent endoscopic sinus surgery (ESS) for FB are presented with literature.

\section{Case Report}

Case 1 - A 74-year-old immunocompetent woman, referred to the neurology polyclinic with complaint of unilateral face pain and headache at the left side. Cranial Computed Tomography (CT) incidentally revealed a heterogenic opacity with calcifications in left maxillary sinus and the patient redirected to the otorhinolaryngology polyclinic. Postnasal drip, and head and left face pain were the main complaints in 


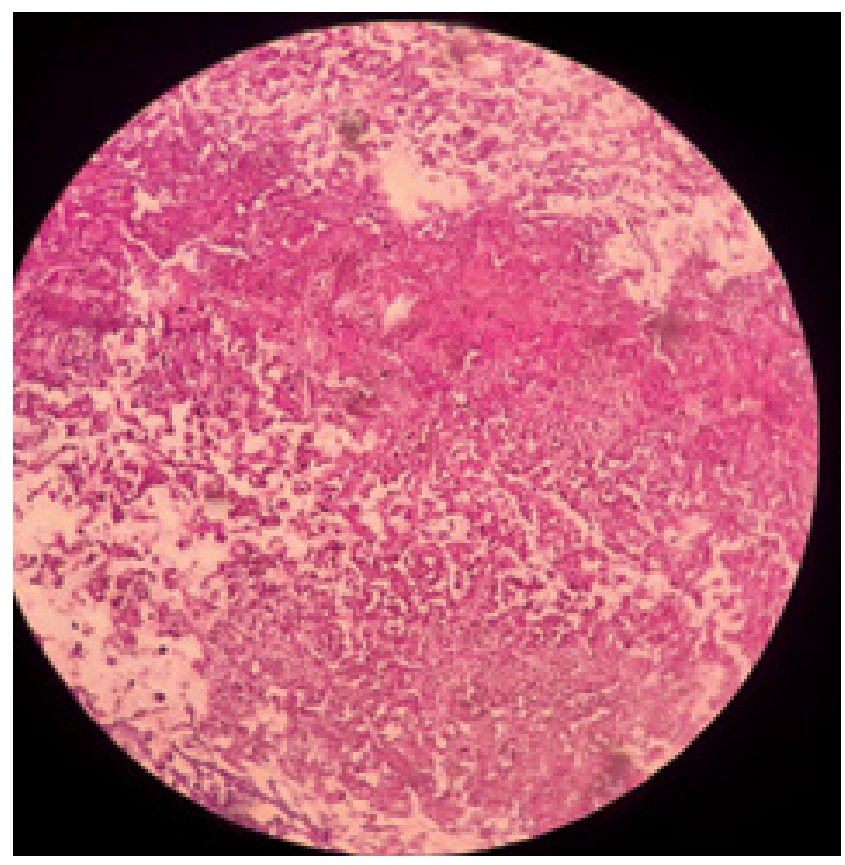

Figure 1. Case 1. Histopathological appearance with p63 staining $X 10$.

the anamnesis. Nasal endoscopy revealed edema at nasal mucosa, obstruction at ostiomeatal complex, left uncinate process was medially protruded. In the light of these signs, left maxillary antrostomy was performed under general anesthesia with prediagnosis of aspergilloma at the left maxillary sinus. It was intraoperatively observed that left uncinate process was protruded medially and ostium of left maxillary sinus was enlarged. After rejection of uncinate process and enlargement of maxillary sinus ostium to anterior and inferior, a green, cheese like material was observed. Left maxillary sinus cavity cleaned completely with the aid of $45^{\circ}$ and $70^{\circ}$ angled endoscopes. There were fungi hyphae and spore colonies at the histopathologic examination. Specimen is reported as aspergilloma (Fig. 1). At the follow-up of 26 weeks, there was no recurrence and severe facial pain was completely relieved.

Case 2 - A 55-year-old immunocompetent male patient; presented with bilateral face pain, intermittent headache, nasal congestion and post nasal dripping. The patient had a history of ESS. Nasal endoscopy showed edema at both sides of ostiomeatal complex and purulent postnasal drip at the left side. CT scan showed total opacification on left maxillary sinus and partial opacification on right maxillary sinus. Calcifications had seen particularly on central part of left maxillary sinus, dense metal foci were present on left maxillary sinus. CT scan also showed bilateral en-

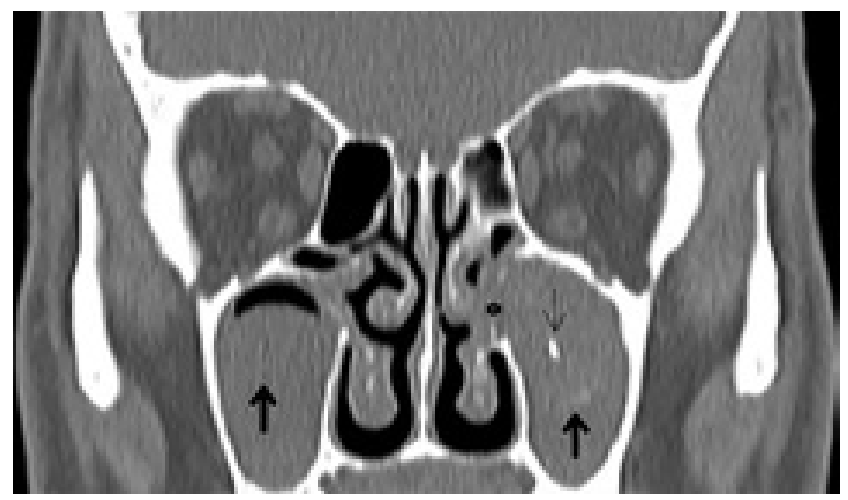

Figure 2. Case 2. Preoperative coronal CT section . Thin black arrow showing metal dense focus and thick black arrows showing microcalsifications. Asterix showing enlarged sinus ostium and protruding fungus material into the nasal cavity.

larged maxillary ostium and there were no signs of erosion on sinus walls (Fig. 2). The patient was taken into the operating room with the prediagnosis of $\mathrm{FB}$ in bilateral maxillary sinus and under general anesthesia ESS was performed. Enlarged maxillary sinus ostiums at both sides observed intraoperatively. We extended both maxillary sinus ostiums towards anterior. Brown, cheese like material was extracted from both maxillary sinuses. Also purulent secretions were seen in bilateral maxillary sinuses. To extract the residual fungus material, anterior side of maxillary sinus was washed with pressurized saline solution using curved aspirator. 45 and 70 degree angled endoscopes used in this process. Histopathological findings of materials extracted from both maxillary sinuses exhibited branched and septated fungal hyphae. These findings are correlated with aspergilloma. There were no post-operative complications. At the control examination after 7 months all symptoms were improved.

Case 3 - A 46-year-old woman applied to the otorhinolaryngology with facial pain on the left side, headache, postnasal drip and bad smell sensation. Left nasal valve obstruction, septum mucosa edema and left ostiomeatal complex edema were observed with nasal endoscopy. There were septoplasty and asthma in the history of patient. Paranasal CT revealed dense heterogenic opacity and calcifications at the center. Left uncinate process was medially protruded and medial part of the left middle concha was absent. With the initial diagnosis of aspergilloma, under the general anesthesia left maxillary antrostomy and septoplasty was performed. After left uncinectomy and enlargement of ostium, sinus cavity was reachable. The green, cheese like purulent 

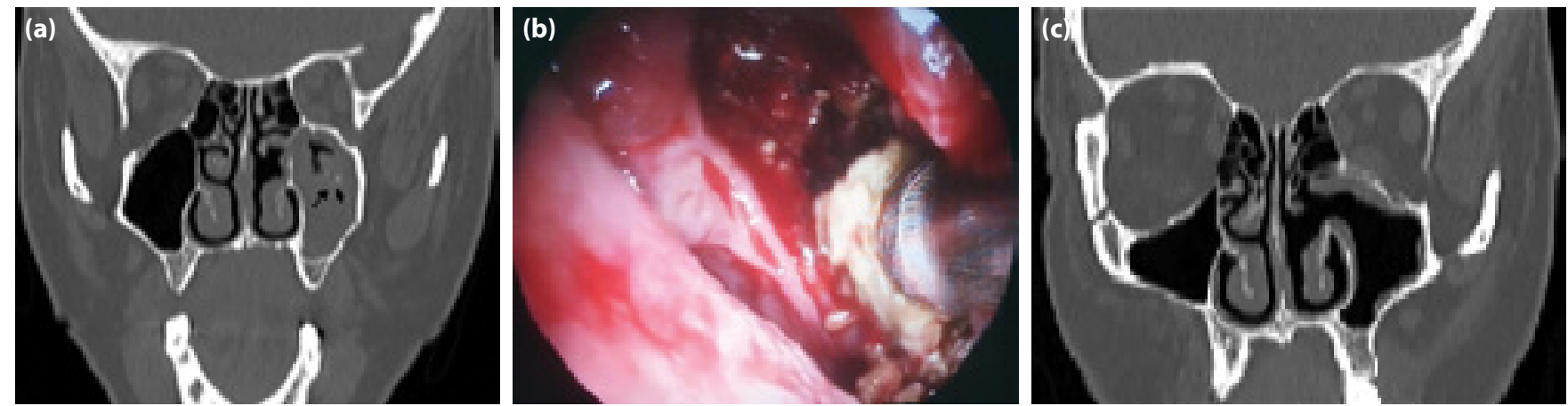

Figure 3. Case 3. (a) Preoperative CT section. (b) Introperative view. Removed fungus material. (c) Postoperative coronal CT.

secretion is cleaned (Fig. 3). At the histopathologic examination, fungus hyphae were observed and reported as aspergilloma. Bad smell sensation and facial pain complaints were improved but postnasal drip persisted at the $6^{\text {th }}$ month follow-up.

\section{Discussion}

Although the incidence of $\mathrm{FB}$ of paranasal sinuses is not yet determined, it is known that the number of reported cases has increased in the past years. ${ }^{[1]}$ The incidence rate is increased for women and also increased for patients with age $>50$. FB is characterized with noninvasive fungal hypha and mucous accumulation in sinuses. ${ }^{[5]}$

Clinical course of FB might be asymptomatic for some patients, but in most cases it causes symptoms depending on the affected sinus. Non-specific clinical symptoms include post-nasal drip, nasal congestion, facial pain, headache and sensation of a bad smell. Retro-orbital pain might be seen in sphenoid sinus FB. As for maxillary sinus, FB symptoms include facial pain on the affected side, feeling of fullness and pain on the eye. ${ }^{[6]}$

Radiological findings of FB are specific. CT scans show heterogenic densities with locally dense calcifications. In a study, comparing sinus FB to chronic sinusitis; CT scans showed calcification and erosion of inner and lateral walls of the sinus is specific to fungus ball. None the less, air-fluid level and mucosal atrophy are not specific signs for FB. ${ }^{[7]}$ In another study, intrasinusal calcification is present at $51 \%$ of FB cases, where less than $3 \%$ of non-fungal maxillary sinusitis cases presents with intrasinusal calcification. ${ }^{[8]}$ The calcification observed at CT of FB is caused by calcium deposits which are the result of metabolic reactions of fungal mass.
For all of the three cases, there were FB in maxillary sinus and for one of those three cases bilateral maxillary sinuses were infected by FB. Facial pain was presented for all the patients while for the second patient facial pain was severe. As non-specific signs, postnasal drip was complaint for all the patients but bad smell sensation was present for just one patient. CT revealed heterogenic density and calcification areas for all the three patients while one patient present with metal dense area at the sinus center.

Similar to our cases, FB is the most common in maxillary sinus. This is because inhaled fungi spores effect the maxillary sinus most. ${ }^{[6]}$ As a second cause, the zinc oxide used for endodontic treatment is blamed as it effects sinus mucosa. It is asserted that as sinus mucosa is effected, fungi materials accumulate in maxillary sinus. ${ }^{[9]}$ There was no history of endodontic treatment in our cases.

Surgery is the gold standard for FB treatment. First choice for treatment of maxillary sinus FB is ESS. Sinus is made reachable by expanding maxillary ostium to anterior and inferior after uncinate process excision. Curved aspirator should be used to take material out from the cavity. In the meantime, $45^{\circ}$ and $70^{\circ}$ angled endoscopes are needed to observe inferior, lateral and anterior walls of the sinus. ${ }^{[10]}$ Although angled endoscopes ease the curettage, reaching to anterior wall is hard. In our cases the hardest wall to clean is the anterior wall. We used Kuhn antrum curette to clean anterior walls, and we used saline to clean the residue as well. New techniques suggested in order to ease the process of cleaning the anterior wall. Despite these precautions, remnant FB occurs in $2 \%$ of cases. ${ }^{[10]}$ There was no recurrence in our long-lasting follow-ups of our cases. 


\section{Conclusion}

FB in maxillary sinus should be considered when a patient present with unilateral face pain. Especially, if the patient is old and the facial pain is persistent, FB should be taken into consideration. Nasal endoscopy may help diagnosis but there are some specific signs for FB. For maxillary sinus FB, ESS is the gold standard. Especially, clearance of anterior, lateral and inferior wall with various kinds of methods will reduce the recurrence rate.

Financial disclosure: The authors declared that this study has received no financial support.

Informed consent: Written informed consent was to be taken from patients who participated in this study.

Conflict-of-interest issues regarding the authorship or article: None declared.

\section{Peer-rewiew: Externally peer-reviewed.}

\section{References}

1. Yoon $\mathrm{YH}, \mathrm{Xu}$ J, Park SK, Heo JH, Kim YM, Rha KS. A retrospective analysis of 538 sinonasal fungus ball cases treated at a single tertiary medical center in Korea (1996-2015). Int Forum Allergy Rhinol 2017;7(11):1070-5. [CrossRef]

2. Dufour X, Kauffmann-Lacroix C, Ferrie JC, Goujon JM, Ro- dier $\mathrm{MH}$, Karkas $\mathrm{A}$, et al. Paranasal sinus fungus ball and surgery: a review of 175 cases. Rhinology 2005;43(1):34-9.

3. Castelnuovo P, Gera R, Di Giulio G, Canevari FR, Benazzo M, Emanuelli E et al. Paranasal sinus mycoses. Acta Otorhinolaryngologica Italica 2000;20(1):6-15. [Article in Italian]

4. Kodama S, Moriyama M, Okamoto T, Hirano T, Suzuki $M$. Isolated frontal sinus aspergillosis treated by endoscopic modified Lothrop procedure. Auris Nasus Larynx 2009;36(1):88-91. [CrossRef]

5. Dufour X, Kauffmann-Lacroix C, Ferrie JC, Goujon JM, Rodier $\mathrm{MH}$, Klossek JM. Paranasal sinus fungus ball: epidemiology, clinical features and diagnosis. A retrospective analysis of 173 cases from a single medical center in France, 1989-2002. Med Mycol 2006;44(1):61-7. [CrossRef]

6. Grosjean P, Weber R. Fungus balls of the paranasal sinuses: a review. Eur Arch Otorhinolaryngol 2007;264(5):461-70.

7. Chen JC, Ho CY. The significance of computed tomographic findings in the diagnosis of fungus ball in the paranasal sinuses. Am J Rhinol Allergy 2012;26(2):117-9. [CrossRef]

8. Yoon JH, Na DG, Byun HS, Koh YH, Chung SK, Dong HJ. Calcification in chronic maxillary sinusitis: comparison of CT findings with histopathologic results. AJNR Am J Neuroradiol 1999;20(4):571-4.

9. Costa F, Polini F, Zerman N, Robiony M, Toro C, Politi M. Surgical treatment of Aspergillus mycetomas of the maxillary sinus: review of the literature. Oral Surg Oral Med Oral Pathol Oral Radiol Endod 2007;103(6):e23-9. [CrossRef]

10. Klossek JM, Serrano E, Péloquin L, Percodani J, Fontanel JP, Pessey JJ. Functional endoscopic sinus surgery and 109 mycetomas of paranasal sinuses. Laryngoscope 1997;107(1):112-7. [CrossRef] 